The Interactive Effect of Anger and Disgust in Moral Outrage and Judgments

\author{
Jessica M. Salerno \\ Arizona State University \\ Liana C. Peter-Hagene \\ University of Illinois at Chicago
}

Authors' note. The authors wish to thank Linda Skitka, Michael Slepian, Paul Conway, Daniel Wisneski, and G. Scott Morgan for their helpful comments on previous drafts. 


\begin{abstract}
Two studies demonstrated that moral outrage is predicted not just from anger, but from a combination of anger and disgust. In Study 1, anger toward moral transgressions (sexual assault, funeral picketing) predicted moral outrage only when it co-occurred with at least moderate disgust, and vice versa. In Study 2, a mock jury paradigm that included emotionally disturbing photographs of a murder victim revealed disgust (versus anger) to be a more consistent predictor-predicting moral outrage at all levels of anger. Further, anger increased confidence in a guilty verdict through moral outrage-but only when co-occurring with at least a moderate level of disgust, whereas disgust increased confidence in a guilty verdict through moral outrage at all levels of anger. The interactive effect of anger and disgust has important implications for theoretical explanations of moral outrage, moral judgments in general, and legal decision making.
\end{abstract}




\section{The Interactive Effect of Anger and Disgust in Moral Outrage and Judgments}

People react to moral transgressions with moral outrage - a constellation of cognitive, affective, and behavioral reactions (Skitka, Bauman, \& Mullen, 2004; Tetlock , Kristel, Elson, Green, \& Lerner, 2000), which influences a variety of important outcomes: retribution and compensation (Carlsmith, Darley, \& Robinson, 2002; Tetlock et al., 2000), political intolerance (Skitka et al., 2004), voting (Okimoto \& Brescoll, 2010), and legal decisions (Salerno et al., 2010). For example, the Westboro Church roused moral outrage in the public by picketing military funerals, bearing signs reading "Thank God for dead soldiers" to communicate their belief that military deaths reflect God's punishment for tolerating homosexuality. Despite our intuitive understanding of what moral outrage is, researchers debate its emotional components. Can the public's reaction be characterized as mere anger, or perhaps a more complex combination of anger and disgust? The current studies investigate whether moral outrage arises from the combination of anger and disgust.

The term "outrage" conjures emotional reactions grounded in anger and, indeed, moral outrage is often operationalized — sometimes exclusively—with anger measures (e.g., Batson et al., 2007; O’Mara et al., 2011; Tetlock et al., 2000). Moreover, some researchers question the existence of "moral outrage" altogether, concluding that it indistinguishable from personal or empathetic anger (Batson et al., 2007; O’Mara et al., 2011). A few studies, however, have included disgust measures in their operationalization of moral outrage (e.g., Okimoto \& Brescoll, 2010). Some researchers include disgust in the definition of moral outrage (e.g., Jensen \& Petersen, 2011) or suggest that disgust could contribute to moral outrage (e.g., Darley \& Pittman, 2003; Mullen \& Skitka, 2006). Further, moral transgressions elicit appraisals associated not only 
with anger, but also disgust (Rozin, Lowery, Imada, \& Haidt, 1999). Disgust is theorized to be a moral emotion (Rozin et al., 1999), often considered a gut feeling (Schnall, Haidt, Clore, \& Jordan, 2008) elicited by purity violations of body or soul (Horberg, Oveis, Keltner, \& Cohen, 2009). Disgust cues (e.g., offensive odors) result in harsher moral judgments (Schnall et al., 2008), and neural regions associated with disgust are likewise associated with moral judgments (Moll et al., 2005). In fact, disgust is sometimes a more consistent emotional reaction to moral violations than is anger (Hutcherson \& Gross, 2011).

Determining whether moral outrage arises from a combination of anger and disgust requires testing both their independent and interactive effects. Assessing the independent roles of anger and disgust in moral judgments is difficult given that they are likely to co-vary (Marzillier \& Davey, 2004) and people sometimes use the term "disgust" interchangeably with "anger" (Nabi, 2002; Olatunji et al., 2012). Researchers have thus highlighted the need to differentiate between their antecedent appraisals and consequences (Hutcherson \& Gross, 2011), measure them simultaneously (Gutierrez \& Giner-Sorolla, 2007), and examine their independent effects on moral judgments by controlling for each statistically (e.g., Horberg et al., 2009). These investigations revealed that anger and disgust can operate differently. For example, violations of bodily norms and taboos elicit disgust, whereas harm elicits anger (Gutierrez \& Giner-Sorolla, 2007), and disgust is more resistant to change in the face of new, mitigating information (Russell \& Giner-Sorolla, 2011).

Despite the frequent co-occurrence of anger and disgust, and the efforts to investigate their independent effects on moral judgments, we are unaware of any studies testing the unique effect of disgust on moral outrage, nor the disgust-anger interactive effect on moral outrage (or on moral judgments in general). Why, theoretically, might anger and disgust interact to produce 
moral outrage? Both anger and disgust are associated with certainty appraisals (Smith \& Ellsworth, 1985), and as a result, both anger (Bodenhausen, Sheppard, \& Kramer, 1994) and disgust (Tiedens \& Linton, 2001) can diminish information processing. Thus, anger and disgust might each exacerbate the effect of the other. For example, increasing anger might lead to increased reliance on visceral gut reactions (disgust) in our judgments and vice versa. Thus, perhaps moral outrage represents a unique combination of anger and disgust in which the two emotions interact to exacerbate each other's influence on judgments.

The primary goal of these studies was to investigate whether moral outrage arises from a combination of disgust and anger by testing the interactive effect of anger and disgust on moral outrage and subsequent judgments. We hypothesized that anger and disgust would predict moral outrage only when each co-occurs with at least a moderate level of the other. Because moral outrage has been identified as an important mediator of anger on downstream social consequences (Skitka et al., 2004), we tested whether moral outrage would mediate the effect of anger and disgust on verdicts in a murder case, and whether each indirect effect would be moderated by the other emotion (Study 2). Specifically, we hypothesized that (a) moral outrage would mediate the effect of anger on murder verdicts, but only when co-occurring with at least moderate disgust, and (b) moral outrage would mediate the effect of disgust on murder verdicts, but only when co-occurring with at least moderate anger.

\section{Study 1}

We assessed anger, disgust, and moral outrage toward two moral transgressions to ensure that the predicted anger and disgust interaction would generalize across more than one moral transgression. Disgust can be elicited by different types of purity violations (e.g., purity violations of body or soul; Horberg et al., 2009). Thus, to ensure that our conclusions about the 
hypothesized anger by disgust interaction would not be limited to only one type of moral transgressions, we included one vignette that included a bodily violation (sexual assault) and another that did not (Westboro Church funeral picketing).

\section{Method}

Participants $\left(N=102 ; M_{\mathrm{age}}=34\right.$ years, $S D=11 ; 50 \%$ women $)$, recruited through Amazon's Mechanical Turk (MTurk.com), read a vignette describing either the sexual assault ( $n$ $=39)$ or funeral picketing $(n=63)$. Participants completed simultaneous measures of how disgusted $(M=4.52, S D=0.95)$ and angry $(M=4.27, S D=1.11)$ they felt about the offender's actions (1-Not at all to 5-Extremely) on a grid designed to discourage people from using "disgust" to label their anger (Figure 1). They then completed four items assessing moral outrage (e.g., "I feel morally outraged toward the defendant," 1 -Not at all to 5-Very much; $\alpha=.62, M=$ $4.57, S D=0.90)$ utilized previously to capture the cognitive, affective, and behavioral components of moral outrage (Skitka et al., 2004). Finally, they completed an open-ended attention check. (See supplementary materials for all Study 1 and 2 materials.)

\section{Results and Discussion}

Bivariate correlations. We examined bivariate correlations among the three variables (Table 1). The significant correlation between anger and disgust was expected given that they are likely to co-vary (Marzillier \& Davey, 2004). The size of these two correlations were only moderately large (Rosenthal \& Rosnow, 1991), however, indicating that—as expected—anger and disgust are not redundant constructs. ${ }^{1}$

Preliminary regression analyses. We conducted preliminary analyses to confirm that our predicted anger and disgust interaction would generalize across the two different moral transgressions. A linear regression confirmed that there was no significant main effect of 
vignette, $B=.11, t(90)=.77, p=55$, and vignette did not interact with anger, $B=.26, t(90)=$ $1.46, p=.15$, or disgust, $B=-.22, t(90)=-.85, p=.40$, nor was the three-way interaction significant, $B=.07, t(90)=.51, p=.61$. Consistent with Aiken and West's (1991) recommendations, we collapsed across the two vignettes by dropping the vignette variable and all vignette interactions from the analysis.

Moral outrage regression analyses. A hierarchical regression revealed that anger was a significant predictor, $B=.23, t(94)=2.66, p<.01$, and disgust was a marginal predictor, $B=.19$, $t(94)=1.85, p=.07$, of moral outrage, $R^{2}=.19, F(2,94)=11.08, p<.001($ Step 1$)$. The interaction entered in Step 2 was significant, $B=.17, t(94)=2.58, p=.01, R^{2}=.24, \Delta R^{2}=.04 .^{2}$ (See Figure 2.)

To probe the interaction, we applied the Johnson-Neyman technique (Hayes \& Matthes, 2009). This is an alternative to more traditional techniques that require the researcher to select two arbitrary values of the moderator at which to assess the significance of the focal predictor (e.g., $1 S D$ above and below the mean, Aiken \& West, 1991). The Johnson-Neyman approach avoids this potentially arbitrary choice by determining not only the point on the moderator continuum at which the focal predictor becomes significant, but also identifies the entire range of moderator values in which the focal predictor is significant or not (Hayes \& Matthes, 2009). Thus, this approach provides a more complete picture of moderation patterns than traditional methods. Specifically, we employed this technique to determine the value of disgust when anger becomes a significant predictor of moral outrage and again to determine the value of anger when disgust becomes a significant predictor of moral outrage (Table 2).

Anger became a stronger predictor of moral outrage as disgust increased, becoming significant when participants' level of disgust reached 3.94 on the 5-point scale. Similarly, 
disgust became a stronger predictor of moral outrage as anger increased, becoming significant when participants' level of anger reached 3.16 on the 5 -point scale. Thus, rather than disgust and anger independently predicting moral outrage, the combination predicted moral outrage. Anger predicted moral outrage only when it co-occurred with at least a moderately high level of disgust; and disgust predicted moral outrage only when it co-occurred with at least a moderately high level of anger. ${ }^{2}$

\section{Study 2}

Study 2 extended Study 1 in two ways. First, we tested the interactive effect of anger and disgust on moral outrage in another scenario that would be likely to elicit anger and disgust in our participants - a gruesome murder. Second, we tested the potential downstream consequences of experiencing anger, disgust and moral outrage on a novel outcome: legal verdicts. Although verdicts are ideally driven by rational weighing of facts, jurors' negative emotions can increase guilty verdicts (e.g., Bright \& Goodman-Delahunty, 2006; for reviews of potential mechanisms, Feigenson \& Park, 2006; Salerno \& Bottoms, 2009). We tested one potential mechanism: A combination of anger and disgust might increase moral outrage, which in turn might increase participants' confidence in a guilty verdict. In support, moral outrage has been identified as an important mediator of the effect of anger on other outcomes. For example, moral outrage mediates the effect of anger on political tolerance (Skitka et al., 2004), and the effect of offense severity on punishment (Carlsmith et al., 2002; Salerno et al., 2010). Further, given that anger predicts both increased moral outrage (Skitka et al., 2004), and guilty verdicts (e.g., BrightGoodman-Delahunty, 2006), we hypothesized that anger would increase moral outrage, which in turn would increase confidence in a guilty verdict. There is no previous research, to our knowledge, that tests whether moral outrage mediates the effect of disgust on subsequent 
judgments_- perhaps because moral outrage research has focused heavily on anger, rather than disgust. Because trait disgust sensitivity predicts participants' estimates of the likelihood that a defendant committed a crime (Jones \& Fitness, 2008), we hypothesized that disgust would also increase moral outrage, which in turn would increase confidence in a guilty verdict.

Similar to the moderation prediction confirmed in Study 1, we predicted that these mediation predictions for each emotion (e.g., the indirect effect of disgust on verdicts through moral outrage) would be moderated by the other emotion (e.g., anger). Because anger and disgust are associated with certainty (Smith \& Ellsworth, 1985) and diminished information processing (Bodenhausen et al., 1994; Tiedens \& Linton, 2001), we hypothesized that anger and disgust might each exacerbate the effect of the other on subsequent judgments. Increasing anger, for example, might lead to increased reliance on visceral gut reactions (disgust) in our verdict judgments and vice versa. Thus, in line with our Study 1 theorizing, we predicted a moderated mediation pattern such that moral outrage would mediate the effects of anger and disgust on confidence in a guilty verdict - but only when each emotion co-occurs with at least a moderate level of the other emotion. That is, the unique interactive pattern of anger and disgust would not only predict moral outrage, but the downstream consequences of moral outrage (i.e., confidence in a guilty verdict).

\section{Method}

In a mock juror study, 118 jury-eligible undergraduates $\left(M_{\mathrm{age}}=19\right.$ years; $63 \%$ women $)$ arrived in a laboratory and viewed a 20 -minute presentation of evidence modified from an actual murder case ( $R v$. Valevski, 2000), including opening and closing statements, testimony from witnesses, photographs and descriptions of knife wounds on the victim's throat, and real jury instructions. Participants completed a combined measure of preferred verdict and confidence on 
a 22-point scale ranging from $100 \%$ confident in "not guilty" to $100 \%$ confident in "guilty"; and

Study 1 measures of disgust $(M=2.20, S D=1.10)$, anger $(M=1.59, S D=0.88)$, and moral outrage $(\alpha=.91, M=1.87, S D=.94)$.

\section{Results and Discussion}

Bivariate correlations. We again examined bivariate correlations among the three variables (Table 1). As expected — and consistent with Study 1—the moderately sized correlation coefficient indicated that anger and disgust were related, but not redundant constructs.

Regression analysis. In a hierarchical regression, disgust, $B=.31, t(106)=4.38, p<$ .001 , and anger, $B=.22, t(106)=3.38, p=.001$, predicted moral outrage, $R^{2}=.31, F(2,106)=$ 23.68, $p<.001$ (Step 1). The interaction in Step 2 was again significant, $B=.16, t(105)=2.33$, $p=.02, \Delta R^{2}=.04$. To probe the interaction, we again used the Johnson-Neyman test, which revealed that, again, anger was a stronger predictor of moral outrage as disgust increased, becoming significant when participants' level of disgust reached 2.87 (Table 3). In contrast, disgust significantly predicted moral outrage at all levels of anger.

We also applied the Johnson-Neyman technique to moderated mediation analyses (Preacher et al., 2007) to determine at what level of (a) disgust the indirect effect of anger on verdicts through moral outrage became significant and, (b) anger the indirect effect of disgust on verdicts through moral outrage became significant (Table 3). The strength of the indirect effect of anger on verdicts through moral outrage increased as disgust increased, and became significant when participants' level of disgust reached 3.12. In contrast, the indirect effect of disgust on verdicts through moral outrage was significant at all levels of anger. (See Supplementary Materials for alternative-model analyses). 
In sum, the combination of anger and disgust again predicted moral outrage. Disgust, however, predicted moral outrage more consistently — from not at all angry to very angrywhereas anger required at least moderate levels of disgust before predicting moral outrage. Critically, as predicted, anger and disgust both increased confidence in a guilty verdict through moral outrage — but the strength of the indirect effect of each emotion depended on the level of the other.

\section{General Discussion}

Two studies confirmed that moral outrage is distinguishable from pure anger by demonstrating that moral outrage results from a combination of anger and disgust-even when the transgression did not include a bodily disgust violation (funeral picketing). Despite often being characterized as the central emotional component of moral outrage, anger predicted moral outrage only when it co-occurred with at least a moderate level of disgust (and vice versa). In fact, disgust was a more consistent predictor of moral outrage in Study 2 - it significantly predicted moral outrage at all levels of anger (even in its absence). This finding might be due to disgust (versus anger) being more resistant to mitigating evidence (Russell \& Giner-Sorolla, 2011), which was presented in Study 2 (i.e., the defense's case), but not in Study 1.

Further, moral outrage mediated the effect of both disgust and anger on judgments with serious real-life consequences: murder verdicts. Anger increased moral outrage, which in turn, increased participants' confidence in a guilty verdict - but only when it co-occurred with at least moderate levels of disgust. Disgust predicted confidence in a guilty verdict through moral outrage, however, at all levels of anger. Because both anger and disgust are associated with certainty appraisals that decrease cognitive processing, each emotion might encourage greater reliance on the other. 
This conceptualization of moral outrage has important theoretical implications, namely that moral outrage is distinguishable from pure anger (cf. Batson et al., 2007). Prior conclusions that the two are indistinguishable might be a result of operationalizing moral outrage with only anger measures, thereby failing to take disgust into account. Furthermore, disgust and anger have different eliciting cues (Russell \& Giner-Sorolla, 2011), underlying cognitive appraisals (Rozin et al., 1999), and action tendencies (Gutierrez \& Giner-Sorolla, 2007), suggesting complex antecedents and processes behind moral outrage that await future investigation.

The implications of our findings extend beyond moral outrage. Despite the effort to differentiate the effects of anger and disgust, this was the first demonstration of an interactive effect of disgust and anger, not only on moral outrage, but on judgments more generally. Given that anger and disgust have competing action tendencies (approach or punishment and avoidance, respectively; Gutierrez \& Giner-Sorolla, 2007), future research could investigate what behavior the combination yields in both moral and non-moral judgments.

Finally, these findings have implications for important real world issues, particularly for the role of emotion and moral outrage in legal decision-making and in how people assign blame for moral transgressions. Although verdicts are ideally driven by rational weighing of evidence, mock jurors' moral outrage toward the defendant explained the effect of both anger and disgust on guilt judgments. Evidence that elicits both anger and disgust (e.g., gruesome photographs, Bright \& Goodman-Delahunty, 2006) might lead jurors' emotions to increase their likelihood of voting guilty by increasing their moral outrage — without necessarily providing any additional information - and therefore should be carefully regulated in court.

Contrary to traditional conceptualizations of moral outrage, these studies suggest that moral outrage is an emotional experience distinguished from anger by the co-experience of 
disgust. Anger, disgust, and their interactive effect should be included in theoretical explanations of moral outrage and moral judgments in general, as well as exploration of their real-world consequence. 


\section{Footnotes}

${ }^{1}$ Because our independent variables were moderately correlated, we conducted collinearity statistics. The results did not merit further investigation (tolerance values $\geq .45$, VIF values $\leq 2.23$ ).

${ }^{2}$ Although we were interested in generalizing across vignettes, for the interested reader we present separate analyses by vignettes. We get similar results if we analyze the vignettes separately. Specifically, the disgust by anger interaction was significant for the sexual assault vignette, $B=.24, t(34)=2.94, p=.01$. Analyses of simple slopes revealed that anger predicts moral outrage at high levels $(0.5 S D$ above the mean $)$ of disgust, $B=.90, t(34)=3.90, p<.001 —$ but, in contrast, not at low levels ( $0.5 S D$ below the mean) of disgust, $B=-.03, t(34)=-.21, p=.81$. Similarly, disgust predicts moral outrage at high levels ( $0.5 S D$ above the mean) of anger, $B=$ $.87, t(34)=3.10, p<.01$ - but, in contrast, not at low levels ( $0.5 S D$ below the mean) of anger, $B$ $=-.22, t(34)=-1.36, p=.18$.

We found consistent results for the funeral picketing vignette-although the anger $\times$ disgust interaction was marginally significant, $B=.18, t(56)=1.72, p=.09$ (most likely because the separate vignette analysis is underpowered). Analyses of simple slopes revealed that anger predicts moral outrage at high levels ( $0.5 S D$ above the mean) of disgust, $B=.50, t(56)=2.22, p$ $=.03$ - but, in contrast, not at low levels ( $0.5 S D$ below the mean) of disgust, $B=-.16 t(56)=-$ $.72, p=.48$. Similarly, disgust predicts moral outrage at high levels ( $0.5 S D$ above the mean) of anger, $B=.94, t(56)=2.25, p=.03$ - but, in contrast, not at low levels ( $0.5 S D$ below the mean) of anger, $B=.16, t(56)=.94, p=.35$. (Note that we had to break down the interaction at $0.5 S D$ above and below the mean for this analysis because breaking down the interaction at $1 S D$ above and below the mean results in values that extend beyond the original 5 -pt scale, and therefore are 
not interpretable.) Further, the anger by disgust interaction remains significant with vignette included as a covariate, $B=.18, t(93)=2.69, p<.01$. Thus, we are confident that our collapsed results for the combined dataset that we report in the main results represent the pattern of results in each separate vignette. 


\section{References}

Aiken, L. S., \& West, S. G. (1991). Multiple regression: Testing and interpreting interactions. Newbury Park, CA: Sage.

Batson, C. D., Kennedy, C. L., Nord, L., Stocks, E. L., Fleming, D. A., Marzette, C. M., Lishner, D. A., Hayes, R. E., Kolchinsky, L. M., \& Zerger, T. (2007). Anger at unfairness: Is it moral outrage? European Journal of Social Psychology, 37, 1272-1285. DOI: 10.1002/ejsp.434.

Bodenhausen, G. V., Sheppard, L. A., \& Kramer, G. P., 1994. Negative affect and social judgment: The differential impact of anger and sadness. European Journal of Social Psychology, 24, 45-62. DOI: 10.1002/ejsp.2420240104.

Bright, D., \& Goodman-Delhunty, J. (2006). Gruesome evidence and emotion: Anger, blame, and jury decision-making. Law and Human Behavior, Special Issue: Emotion in legal judgment and decision making, 30, 183-202. DOI 10.1007/s10979-006-9027-y.

Carlsmith, K. M., Darley, J. M., \& Robinson, P. H. (2002). Why do we punish? Deterrence and just deserts as motives for punishment. Journal of Personality and Social Psychology, 83, 284-299. DOI: 10.1037//0022-3514.83.2.284.

Darley, J. M., \& Pittman, T. S. (2003). The psychology of compensatory and retributive justice. Personality and Social Psychology Review, 7, 324-336. DOI: 10.1207/S15327957PSPR0704_05

Feigenson, N, \& Park, J. (2006). Emotions and attributions of legal responsibility and blame: A research review. Law and Human Behavior. Special Issue: Emotion in legal judgment and decision making, 30, 143-161. DOI: 10.1007/s10979-006-9026-Z.

Gutierrez, R., \& Giner-Sorolla, R. (2007). Anger, disgust, and presumption of harm as reactions 
to taboo-breaking behaviors. Emotion, 7, 853-868. DOI: 10.1037/1528-3542.7.4.853.

Hayes, A. F., \& Matthew, J. (2009). Computational procedures for probing interactions in OLS and logistic regression: SPSS and SAS implementation. Behavior Research Methods, 41, 924-936. DOI: 10.3758/BRM.41.3.924.

Horberg, E. J., Oveis, C., Keltner, D., Cohen, A. B. (2009). Disgust and the moralization of purity. Journal of Personality and Social Psychology, 97, 963-976. DOI:

10.1037/a0017423.

Hutcherson, C. A., \& Gross, J. J. (2011). The moral emotions: A social-functionalist account of anger, disgust, and contempt. Journal of Personality and Social Psychology, 100, 719-737. DOI: $10.1037 / \mathrm{a} 0022408$.

Jensen, N. H., \& Petersen, M. B. (2011). To defer or to stand up? How offender formidability affects third party moral outrage. Evolutionary Psychology, 9, 118-136. URL: http://proxy.cc.uic.edu/docview/900621838?accountid=14552.

Jones, A., \& Fitness, J. (2008). Moral hypervigilance: The influence of disgust sensitivity in the moral domain. Emotion, 8, 613-627. DOI: 10.1037/a0013435.

Lerner, J. S., Dahl, R. E., Hariri, A. R., \& Taylor, S. E. (2007). Facial expressions of emotion reveal neuroendocrine and cardiovascular stress responses. Biological Psychiatry, 61, 253260. DOI: 10.1016/j.biopsych.2006.08.016.

Marzillier, S. L., \& Davey, G. C. (2004). The emotional profiling of disgust-eliciting stimuli: Evidence for primary and complex disgust. Cognition and Emotion, 18, 313-336. DOI: 10.1080/02699930341000130.

Moll, J., Oliveira-Souza, R., Moll, F. T., Ignacio, F. A., Bramanti, I. E., Caparelli-Daquer, E. M., Eslinger, P. J., 2005. The moral affiliations of disgust: A functional MRI study. Cognitive 
and Behavioral Neurology, 18, 68-78. DOI: 10.1097/01.wnn.0000152236.46475.a7.

Mullen, E., \& Skitka, L. J. (2006). Exploring the psychological underpinnings of the moral mandate effect: Motivated reasoning, group differentiation, or anger? Journal of Personality and Social Psychology, 90, 629-643. DOI: 10.1037/0022-3514.90.4.629.

Nabi, R. L. (2002). The theoretical versus the lay meaning of disgust: Implications for emotion research. Cognition \& Emotion, 16, 695-703. DOI:10.1080/02699930143000437.

Okimoto, T. G., \& Brescoll, V. L. (2010). The price of power: Power seeking and backlash against female politicians. Personality and Social Psychology Bulletin, 36, 923-936. DOI: $10.1177 / 0146167210371949$.

Olatunji, B. O., Adams, T., Ciesielski, B., David, B., Sarawgi, S., \& Broman-Fulks, J. (2012). The three domains of disgust scale: Factor structure, psychometric properties, and conceptual limitations. Assessment, 19, 205-225. DOI: 10.1177/1073191111432881.

O’Mara, E. M., Jackson, L. E., Batson, C. D., Gaertner, L. (2011). Will the real moral outrage stand up? Distinguishing among emotional reactions to a moral violation. European Journal of Social Psychology, 41, 173-179. DOI: 10.1002/ejsp.754.

Preacher, K. J., Rucker, D. D., \& Hayes, A. F. (2007). Assessing moderated mediation hypotheses: Theory, methods, and prescriptions. Multivariate Behavioral Research, 42, 185227. DOI: $10.1080 / 00273170701341316$.

Rozin, P., Lowery, L., Imada, S., \& Haidt, J. (1999). The CAD triad hypothesis: A mapping between three moral emotions (contempt, anger, disgust) and three moral codes (community, autonomy, divinity). Journal of Personality and Social Psychology, 76, 574 -586. DOI: 0022-3514/99.

Russell, P. S., \& Giner-Sorolla, R. (2011). Moral anger is more flexible than moral disgust. 
Social Psychological and Personality Science, 2, 360-364. DOI:

10.1177/1948550610391678.

Salerno, J. M., \& Bottoms, B. L. (2009). Emotional evidence and jurors' judgments: The promise of neuroscience for informing psychology and law. Behavioral Sciences and the Law: Special Issue: The Neuroscience of Decision Making and Law, 27, 273-296. DOI: 10.1002/bsl.861.

Salerno, J. M., Najdowski, C. J., Stevenson, M. C., Wiley, T. R. A., Bottoms, B. L., Vaca Jr., R., Pimentel, P. S. (2010). Psychological mechanisms underlying support for juvenile sex offender registry laws: Prototypes, moral outrage, and perceived threat. Behavioral Sciences and the Law, 28, 58-83. DOI: 10.1002/bsl.921.

Schnall, S., Haidt, J., Clore, G. L., \& Jordan, A. H., 2008. Disgust as embodied moral judgment. Personality and Social Psychology Bulletin, 34, 1096 - 1109.

DOI: $10.1177 / 0146167208317771$.

Skitka, L. J, Bauman, C. J., \& Mullen, E., 2004. Political tolerance and coming to psychological closure following the September 11, 2001, terrorist attacks: An integrative approach. Personality and Social Psychology Bulletin, 30, 743-756. DOI: $10.1177 / 0146167204263968$.

Smith, C. A., \& Ellsworth, P. C. (1985). Patterns of cognitive appraisal in emotion. Journal of Personality and Social Psychology, 48, 813-838. DOI: 10.1037/0022-3514.48.4.813.

Tetlock, P. E., Kristel, O. V., Elson, S. B., Green, M. C., \& Lerner, J. S. (2000). The psychology of the unthinkable: Taboo trade-offs, forbidden base rates, and heretical counterfactuals. Journal of Personality and Social Psychology, 78, 853-870. DOI: 10.1037//00223514.78 .5 .853 
Tiedens, L. Z., \& Linton, S. (2001). Judgment under emotional uncertainty: The effects of specific emotions on information processing. Journal of Personality and Social Psychology, 81, 973-988. DO1: 10.1037//OO22-3514.81.6.973. 